\title{
Study on the thermodynamic properties of nickel-cobalt ore bio-leaching solution
}

\author{
Zhou Guiying $^{1, a}$, Hou Chuyue ${ }^{1, b}$, Wen Jiankang ${ }^{1, c}$ \\ ${ }^{1}$ National Engineering Lab.of Biohydrometallurgy, General Research Institue for Nonferous Metals \\ No.2 Xinjiekou Wai Da Street,Beijing,.China \\ azhouguiying2001@163.com, bhouchuyue@126.com, 'kang3412@126.com
}

\begin{abstract}
Keywords: Conductivity; activity coefficient; bioleaching solution; nickel-Cobalt
Abstract. Researches about the separation process of valuable metals for nickel-cobalt ore bio-leaching solution had already been continuously studied, while studies about its thermodynamic properties has not been carries out. This paper conducted research about thermodynamic properties including conductivity, activity coefficient of nickel-cobalt ore bio-leaching solution. Conductivity of nickel and cobalt in bio-leaching solution system was determined with conductivity method at a temperature range from $298 \mathrm{~K}$ to $313 \mathrm{~K}$. The mean activity coefficient of nickel-cobalt in bioleaching solution was calculated with relative formula, and effect of the temperature and the concentration to the mean activity coefficient have been discussed. The comparison of thermodynamic properties has been researched in presence of bacteria and aseptic condition. To reflect the solution components' effect on its thermodynamic state, this paper used the Meissner-Pitzer Model to analyze the variation rule of the activity coefficient, and quantified change of thermodynamic properties of the system when the $\mathrm{pH}$ value and ion concentration changed.
\end{abstract}

\section{Introduction}

Through a large number of condition experiments and kinetic studies, researchers improved the separation and enrichment processes of valuable metal ions from bioleaching solution of waste materials like the lean ore, waste rock, ore tailings and waste batteries. Such studies indeed called attention from researchers ${ }^{[1]}$, yet still rare, lacking related data. As we know, Activity coefficient of electrolytic is one of most important thermodynamic properties in the solution system ${ }^{[2]}$.

Concerning the thermodynamic model of electrolyte, Based on Debye and Hückel theory, the Pizer theory made the most important development in this field ${ }^{[3]}$ after which Pizer and other researchers consistently developed the Pizer equation, helping the Pizer theory suitable for systems with higher concentration, greater pressure and various mixtures ${ }^{[4]}$. Currently models used for calculating thermodynamics of mixed electrolytes include the Pizer Model, the Meissner Model, the Chen Model, the Frank-Thompson Model and so on. Among all these models, the Meissner Model is easy to calculate, not requiring mixed parameter. Yet it owns low accuracy. However, considering its convenience, it is one of the practical tools for study on thermodynamic properties of the bioleaching solution, with proper amendments ${ }^{[5]}$.

\section{Experimental Materials and Methods}

\section{Experiment Materials}

The actual bioleaching solution is from a low grade nickel-cobalt ore in Jilin Baishan. Its components are showed by Table 1 .

Table 1 Concentration of major elements in the bioleaching solution

\begin{tabular}{|ccccccc|}
\hline Element & $\begin{array}{c}\mathrm{Ni}^{2+} \\
/\left(\mathrm{g} \cdot \mathrm{L}^{-1}\right)\end{array}$ & $\begin{array}{c}\mathrm{Co}^{2+} \\
/\left(\mathrm{g} \cdot \mathrm{L}^{-1}\right)\end{array}$ & $\begin{array}{c}\mathrm{Fe}^{3+} \\
/\left(\mathrm{g} \cdot \mathrm{L}^{-1}\right)\end{array}$ & $\begin{array}{c}\mathrm{Fe}^{2+} \\
/\left(\mathrm{g} \cdot \mathrm{L}^{-1}\right)\end{array}$ & $\begin{array}{c}\mathrm{Ca}^{2+} \\
/\left(\mathrm{g} \cdot \mathrm{L}^{-1}\right)\end{array}$ & $\begin{array}{c}\mathrm{Mg}^{2+} \\
/\left(\mathrm{g} \cdot \mathrm{L}^{-1}\right)\end{array}$ \\
\hline Content & 1.90 & 0.22 & 4.52 & 5.13 & 0.39 & 14.76 \\
\hline
\end{tabular}




\section{Experiment Methods}

The conductivity have been measured by conductivity meter $308 \mathrm{~F}$ instrument, Using calibration constant of conductance pool is 1.044 . It has been measured by a constant- temperature bath trough balance model.

The mean activity coefficient of nickel-cobalt in bioleaching solution was calculated with Meissner-Pitzer Model, and effect of the temperature and the concentration to the mean activity coefficient have been discussed.

\section{Results and Discussion}

Measurement of conductivity rate in condition of different system

The test results showed that the change regulation of conductivity rate in condition of different $\mathrm{pH}$ and temperature.
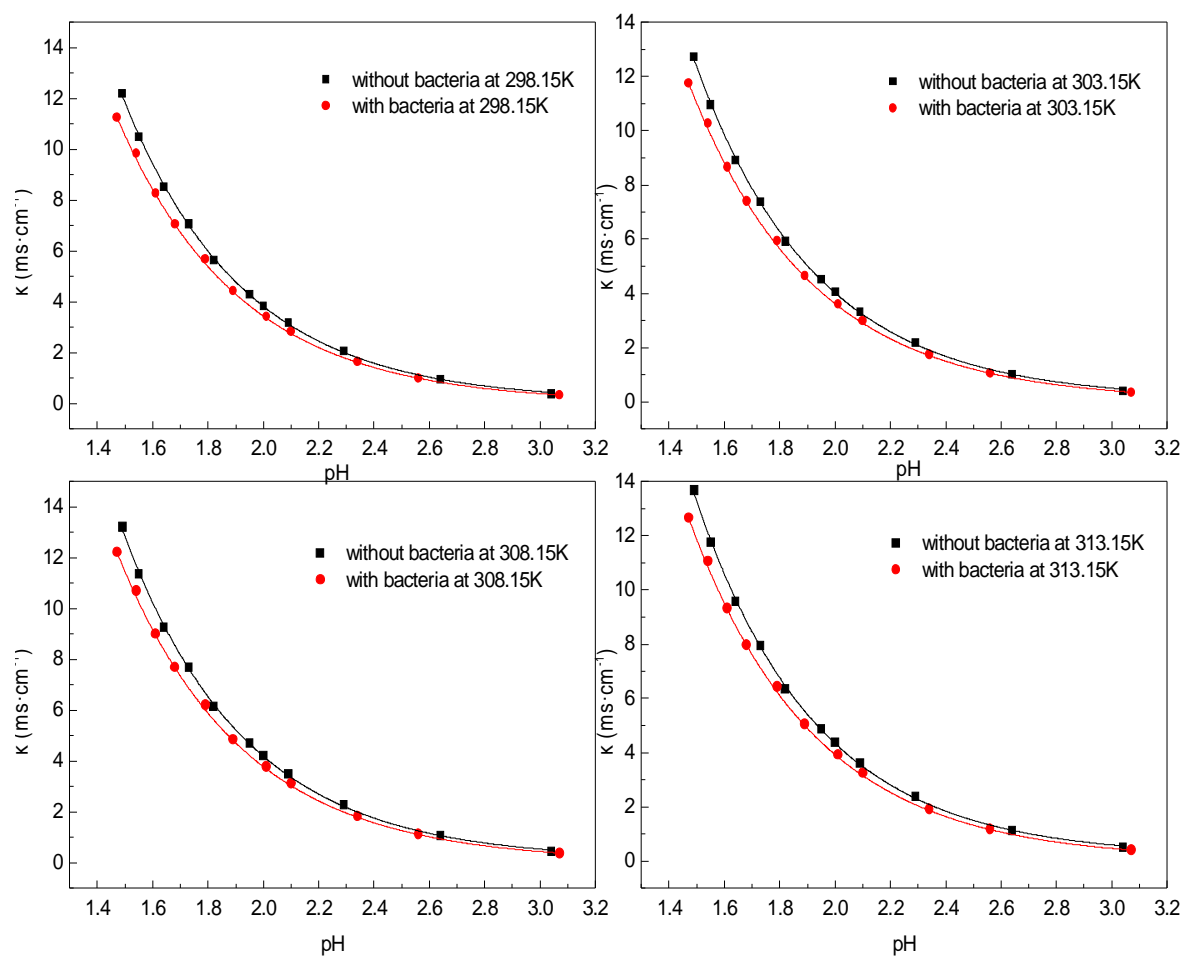

Fig.1 Effect of conductivity rate to $\mathrm{pH}$ value and temperature in different system

The results indicated that when the concentration was certain, the conductivity rate decreased with the rising $\mathrm{pH}$ value as Figure 1. And leaching bacteria, as a composition of the leaching solution, had no obvious effect to conductivity rate, while change of $\mathrm{pH}$ value was an important cause for conductivity rate variation. So it can be conclude that bacteria will not significantly change the conductivity rate in bioleaching solution system.

\section{The change regulation of conductivity rate in different leaching system}

It has been set up parallel experiments during shaking table leaching. It would obtain differences of conductivity properties between of bacteria leaching solution and aseptic leaching solution.

The results indicated that the conductivity rate increased with the rising the ion concentration and temperature as Figure 2.The ion concentration in leaching solution was an important effective faction for conductivity rate. The difference of conductivity rate was little between chemical leaching solution and bioleaching solution. 


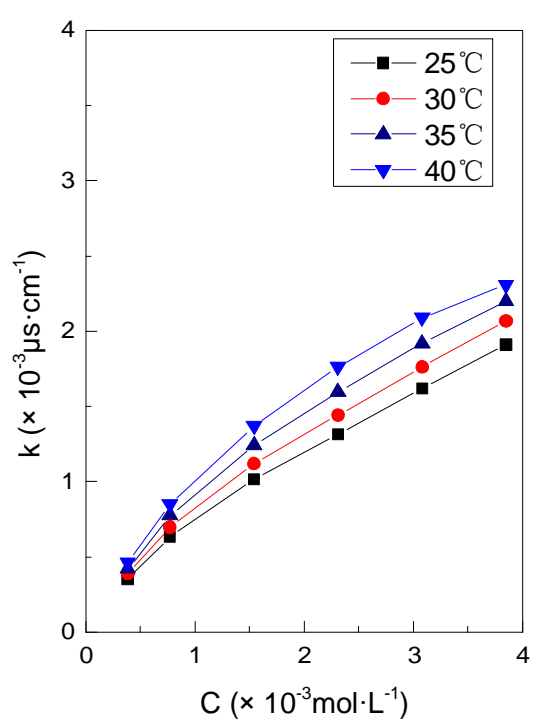

(a)

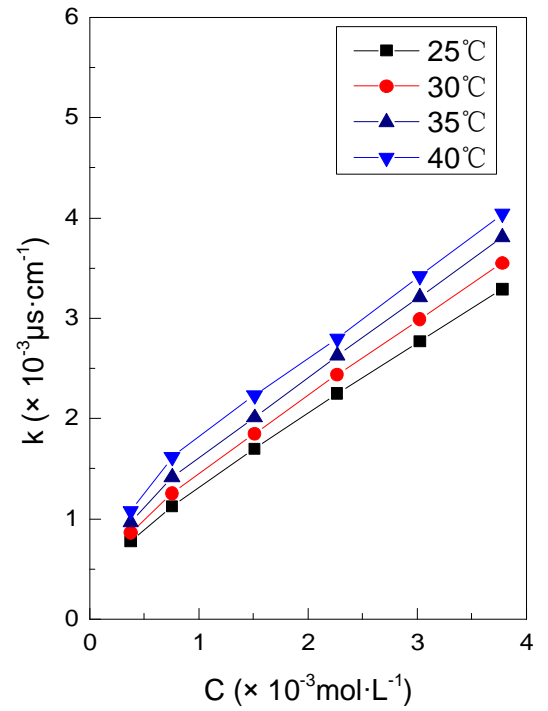

(b)

Fig.2 Effect of conductivity rate on concentration and temperature in different leaching system

(a)bioleaching solution; (b)chemical leaching solution

\section{The change regulation of activity coefficient in different leaching system}

Results indicated that when the concentration was certain, the average activity coefficient decreased with the rising temperature. And when the temperature was certain, it decreased with the rising electrolytes concentration.

To reflect the solution components' effect on its thermodynamic state, this paper used the Meissner-Pitzer Model to analyze the variation rule of the activity coefficient, and quantified change of thermodynamic properties of the system when the $\mathrm{pH}$ value and ion concentration changed. Prediction of the Model was consistent with the actual experimental results.

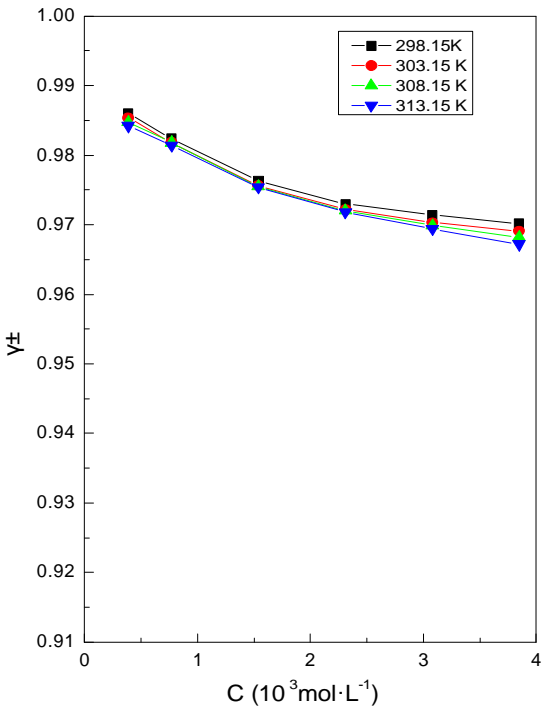

(a)

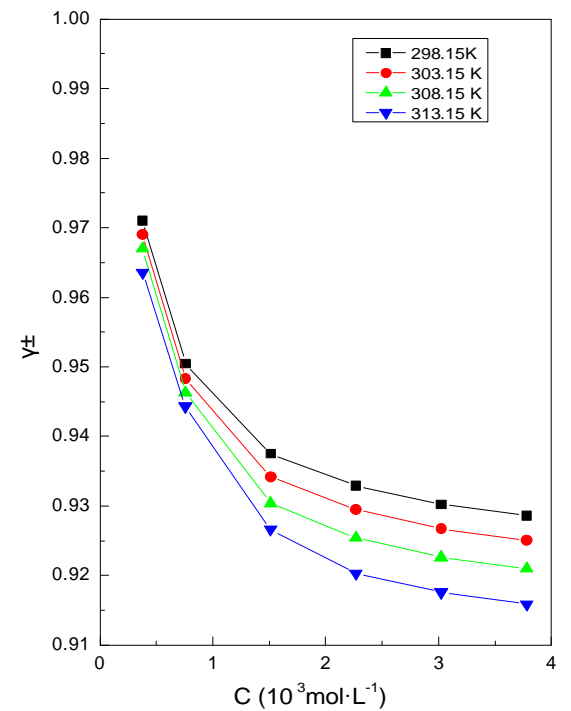

(b)

Fig.3 Effect of activity coefficient on concentration and temperature in different leaching system (a)bioleaching solution; (b)chemical leaching solution 


\section{Conclusions}

The study of mean activity coefficients of electrolytes in the mixed solvent is of important significance in establishment or optimization the hydrometallurgical. The activity coefficients of the related systems of nickel and cobalt sulfate are determined by the conductivity method in different system. The experiment result indicated that leaching bacteria, as a composition of the leaching solution, had no obvious effect to conductivity rate. The change regulation of activity coefficient in different leaching system was obtained.

\section{Acknowledgements}

This work was financially supported by the National Program on Key Basic Research Project (973 Program: 2010CB630906) and Enterprise technology innovation fund project(2015-GX-Q06A)

\section{References}

[1] Wang Qinping,Zhang Chunli, Chen Hongtao. Chinese journal of applied chemistry. Vol.20:11(2003), p.1071-1075

[2] Chen Xiang, Liu Shijun, Huang Huaqiang. Journal of Natural Science of Hunan Normal University.Vol.37:5(2014), p. 43-48

[3] Partanen J.I.. Journal of Chemical \& Engineering Data, Vol. 54:3(2009), p.882-889.

[4] Kobylin P. Thermodynamic modeling of aqueous metal sulfate solutions[d]. Aalto University, (2013),p.21-25.

[5] Wu R., Oliazadeh M., Alfantazi A.M. Journal of Applied Electrochemistry, Vol.33:11(2003):1043-1047. 